\title{
Genetic and environmental sources of familial coaggregation of obsessive-compulsive disorder and suicidal behavior: a population-based birth cohort and family study
}

\author{
Anna Sidorchuk $\mathbb{D}^{1} \cdot$ Ralf Kuja-Halkola $\mathbb{D}^{2} \cdot$ Bo Runeson ${ }^{3} \cdot$ Paul Lichtenstein $\mathbb{D}^{2} \cdot$ Henrik Larsson ${ }^{2,4}$.

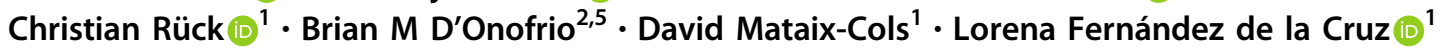

Received: 5 December 2018 / Revised: 5 March 2019 / Accepted: 25 March 2019 / Published online: 8 April 2019

(c) The Author(s) 2019. This article is published with open access

\begin{abstract}
Obsessive-compulsive disorder (OCD) is associated with high risk of suicide. It is yet unknown whether OCD and suicidal behaviors coaggregate in families and, if so, what are the mechanisms underlying this coaggregation. In a population-based birth cohort and family study, we linked individuals born in Sweden in 1967-2003 $(n=3,594,181)$ to their parents, siblings, and cousins, and collected register-based diagnoses of OCD, suicide attempts, and deaths by suicide and followed them until December 31, 2013. We also applied quantitative genetic modeling to estimate the contribution of genetic and environmental factors to the familial coaggregation of OCD and suicidal behavior. An elevated risk of suicide attempts was observed across all relatives of individuals with OCD, increasing proportionally to the degree of genetic relatedness, with odds ratios (OR) ranging from 1.56 (95\% confidence interval (CI) 1.49-1.63) in parents to 1.11 (95\% CI 1.07-1.16) in cousins. The risk of death by suicide also increased alongside narrowing genetic distance, but was only significant in parents (OR 1.55; 95\% CI $1.40-1.72$ ) and full siblings (OR 1.80; 95\% CI 1.43-2.26) of individuals with OCD. Familial coaggregation of OCD and suicide attempts was explained by additive genetic factors (60.7\%) and non-shared environment (40.4\%), with negligible contribution of shared environment. Similarly, familial coaggregation with death by suicide was attributed to additive genetics $(65.8 \%)$ and nonshared environment (34.2\%). Collectively, these observations indicate that OCD and suicidal behaviors coaggregate in families largely due to genetic factors. The contribution of unique environment is also considerable, providing opportunities to target high-risk groups for prevention and treatment.
\end{abstract}

Supplementary information The online version of this article (https:// doi.org/10.1038/s41380-019-0417-1) contains supplementary material, which is available to authorized users.

Anna Sidorchuk

anna.sidorchuk@ki.se

1 Centre for Psychiatry Research, Department of Clinical Neuroscience, Karolinska Institutet, \& Stockholm Health Care Services, Stockholm County Council, Stockholm, Sweden

2 Department of Medical Epidemiology and Biostatistics, Karolinska Institutet, Stockholm, Sweden

3 Centre for Psychiatry Research, Department of Clinical Neuroscience, Karolinska Institutet, \& Stockholm Health Care Services, Stockholm County Council, S:t Görans Hospital, SE-112 61 Stockholm, Sweden

4 School of Medical Sciences, Örebro University, Örebro, Sweden

5 Department of Psychological and Brain Science, Indiana University, Bloomington, IN, USA

\section{Introduction}

Recent evidence suggests that obsessive-compulsive disorder (OCD) is associated with a substantial risk of suicidal behavior, including high rates of suicidal attempts and death by suicide [1-5]. However, the mechanisms that may underlie the association between OCD and suicidal behaviors remain to be explored.

Both OCD and suicidal behaviors aggregate in families. Family and twin studies suggest that susceptibility to OCD is due to both genetic and nonshared environmental factors in equal proportion, while the contribution of shared environment seems to be negligible [6-8]. The familial clustering of suicide has shown to be primarily influenced by genetic and also shared environmental factors [9-13]. One yet unexplored possibility is that OCD and suicidal behaviors might share genetic and/or environmental risk factors, as shown in other psychiatric disorders. For example, a substantial contribution of shared genetic factors 
is reported for coaggregation of suicidal behavior and eating disorders [14], while shared genetic factors along with limited but plausible influence of familial environment are suggested to explain a coaggregation of attention-deficit/ hyperactivity disorder with suicide attempts [15]. The study of such etiological aspects may contribute to the development of more effective ways of identifying and modifying the risk of suicide in OCD, particularly if the familial coaggregation between OCD and suicidal behavior is not entirely explained by genetic factors.

This population-based study of over 3 million Swedes examined whether OCD and suicidal behaviors coaggregate in families, and employed quantitative genetic modeling methods to estimate the contribution of genetic and environmental factors to such familial coaggregation.

\section{Methods}

The study was approved by the Regional Ethics Review Board in Stockholm, Sweden (Reference number 2013/862$31 / 5)$. The requirement for informed consent was waived because the study was register-based and the included individuals were not identifiable at any time.

\section{Swedish national registers and study population}

We conducted a population-based birth cohort and family study by linking the following nationwide Swedish registers via the unique personal identification number assigned to all Swedish residents [16]: the Multi-Generation Register (MGR) [17], the National Patient Register (NPR) [18], the Cause of Death Register (CDR) [19], the Total Population Register (TPR), and the Migration Register [20]. Details about these registers are given in the Supplementary information.

The study population consisted of all individuals born in singleton births in Sweden between January 1, 1967 and December 31, 2003 with information on both biological parents $(n=3,710,392)$. We excluded individuals who were adopted or had died or emigrated from Sweden before age 6 years. The final cohort included 3,594,181 individuals who were followed up until December 31, 2013.

\section{Family-level data}

For each cohort member, five clusters of biological relatives were identified via the MGR: parents, full siblings (defined if they shared both parents), maternal half siblings (if they shared the same mother), paternal half siblings (if they shared the same father), and full cousins (if they shared a grandmother and grandfather). Siblings and cousins were nested in the final cohort. Parents were excluded from the analysis of parental cluster if one or both died or emigrated from Sweden before 1973 (i.e., before the full coverage of psychiatric disorders in the NPR) and did not return. Each person could appear multiple times in different clusters (e.g., parent, sibling, and cousin) and several relative pairs could be descended from one individual (e.g., in case of having several siblings). In each pair, we defined the person used for establishing the family relationship as the "proband", with parents, siblings or cousins defined as "relatives". Family identification numbers were created to link the relatives.

\section{Measures}

Lifetime OCD diagnoses were retrieved from the NPR based on International Classification of Disorders (ICD) codes (see Supplementary Table 1). The ICD-10 codes for OCD have shown high validity, with moderate validity for ICD-8 and ICD-9 [21]. To avoid diagnostic misclassification, diagnoses were collected if recorded at age 6 years or above.

Suicide attempts with certain or undetermined intent were also identified from the NPR based on ICD-8/9/10 codes (see Supplementary Table 1) [2, 22]. Deaths by suicide were identified via the CDR as any records of suicide or external cause of death with undetermined intent by the same ICD codes (see Supplementary Table 1). Undetermined attempts and deaths were included to reduce underestimation of suicidal behavior [23-25]. Data on suicide attempts or deaths by suicide were collected if recorded at age 10 years or above to avoid inclusion of misclassified events [22, 26].

We collected data on lifetime psychiatric comorbidities given their known impact on suicidal behavior [27, 28]. The ICD codes for affective disorders, anxiety disorders, personality disorders, substance use disorders, psychotic disorders, and "other" psychiatric disorders, including reaction for severe stress, adjustment, dissociative, somatoform and other neurotic disorders, were retrieved from the NPR, if recorded at age 6 years or above (see Supplementary Table 1). Sex and year of birth (continuous variable, further categorized by 10 -year increments) were retrieved from the TPR.

\section{Statistical analysis}

Differences in clinical characteristics by OCD status were ascertained for the whole cohort and within gender strata with chi-square test and Fisher's exact test for categorical variables and independent-sample two-tailed $t$ tests for continuous variables. We quantified the association of OCD with suicide attempts and, separately, deaths by suicide in the total cohort and in each relative cluster, using logistic 
Table 1 Number of individuals in the study cohort and each cluster of relatives

\begin{tabular}{lllll}
\hline Total cohort and family clusters & Unique individuals & Unique pairs $^{\mathrm{a}}$ & Observations $^{\mathrm{b}}$ & Excluded $^{\text {Nat }}$ \\
\hline Total cohort & $3,594,181$ & $\mathrm{NA}$ & $3,594,181$ & $\mathrm{NA}$ \\
Parents-offspring & $3,560,020$ & $3,560,020$ & $3,560,020$ & $34,161^{\mathrm{c}}$ \\
Full siblings & $2,726,045$ & $2,071,762$ & $4,143,524$ & $868,136^{\mathrm{d}}$ \\
Maternal half siblings & 471,824 & 357,365 & 714,730 & $3,122,357^{\mathrm{d}}$ \\
Paternal half siblings & 512,484 & 416,289 & 832,578 & $3,081,697^{\mathrm{d}}$ \\
Full cousins & $2,358,636$ & $6,917,441$ & $13,834,882$ & $1,235,545^{\mathrm{e}}$ \\
\hline
\end{tabular}

Note: In all pairs of siblings and cousins, each individual contributed to the analysis, at least once, with information on exposure (OCD) and on outcome (suicide outcomes). Parents were measured on their suicide outcomes and offspring on OCD status

$N A$ not applicable, $O C D$ obsessive-compulsive disorder

${ }^{a}$ Number of the unique pairs identified (e.g., Parents-Offspring, Sibling1-Sibling2)

${ }^{b}$ Number of observations included in the analysis (i.e., all possible combinations of pairs in which members contribute to the analysis with information on OCD and suicide attempts and/or death by suicide: for example,

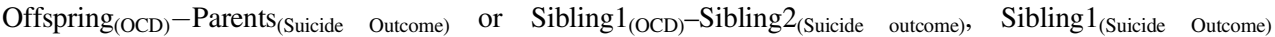
-Sibling2 (OCD)

cProbands whose one or both parents died or emigrated from Sweden before 1973 and never returned

${ }^{\mathrm{d}}$ Probands with no siblings of a certain degree of relatedness identified from the study cohort

e Probands with no full cousins identified from the study cohort or if parents of full cousins are twins regression to obtain odds ratio (ORs) and corresponding 95\% confidence intervals (CIs) [29]. All analyses were clustered by family identification number and a robust sandwich estimator of standard errors was used to account for nonindependence between repeated observations within families [30, 31].

In the total cohort, we compared the odds of having suicide outcomes in individuals with OCD to the odds in their counterparts without OCD in a model adjusted for sex and year of birth (categorical). Interactions between OCD and sex were detected in association with suicide attempts $(p<0.001)$ and death by suicide $(p=$ 0.001 ) and therefore the results are presented separately for males and females. No significant interactions with sex of either probands or relatives appeared in the analyses of relative clusters.

In each relative cluster, we assessed the odds of attempting suicide and dying by suicide in relatives of OCD-probands in comparison to relatives of unaffected individuals, controlling for sex and year of birth (categorical) of both probands and relatives (only for proband's sex and year of birth in parental cluster). Higher odds of suicide outcomes in relatives of OCD-probands indicate the contribution of shared genetics and environment to familial coaggregation of the disorders. The following assumptions on the source of coaggregation were made: (i) parents share $50 \%$ of additive genetic factors with offspring and provide the early rearing environment; (ii) full siblings share on average $50 \%$ of additive genetic factors and $100 \%$ of environmental factors; (iii) maternal half siblings share on average $25 \%$ of genetic factors and $100 \%$ of environmental factors; (iv) paternal half siblings share on average $25 \%$ of genetic factors and less than $100 \%$ of environmental factors; and (v) full cousins share on average $12.5 \%$ of genetic factors and $0 \%$ of environment [32]. The proportions of shared environment have been suggested since in Sweden children predominantly reside with mothers after parental separation and cousins rarely reside together [33].

The importance of genetic factors in familial coaggregation is suggested if significant association is observed in full cousins or if an association among full siblings is stronger than that in maternal half siblings. A contribution of shared environment is inferred if an association is stronger in maternal than in paternal half siblings. No difference between maternal and paternal half siblings in combination with significantly stronger association in full siblings additionally indicates the importance of genetic factors. In our study, we focused specifically on singletons due to their genuine difference with twins in intrauterine and perinatal conditions, as these conditions have shown to impact the risk of OCD [34] and suicidal behaviors [35]. Furthermore, from full cousins' cluster we excluded individuals whose parents were twins because the offspring of monozygotic twins share $25 \%$ of genetic factors. Table 1 presents the total number of individuals in the analyses.

\section{Sensitivity analyses}

Three sets of analyses were performed to check the robustness of our results. First, we explored whether familial coaggregation was better explained by the direct effect of OCD on suicide outcomes within an individual. 
We re-analyzed each relative cluster after excluding probands with any suicide attempt or a record of death by suicide and relatives with OCD [14, 36, 37]. Second, we examined the extent to which the associations within clusters were explained by comorbidities. For that, we excluded probands and relatives with comorbid psychiatric disorders (one disorder at the time). Finally, we explored whether the results were biased by differential follow-up time and re-run the analyses in the total cohort and in siblings and cousins after excluding those who emigrated or died from reasons other than suicide during the follow-up.

\section{Quantitative genetic modeling}

Separately for each suicide outcome, we measured the contribution of genetic and environmental factors to familial coaggregation with OCD using quantitative genetic modeling [37-39]. Structural equation modeling was used to decompose variance and covariance into additive genetic (A), dominant genetic (D), shared environmental (C), and nonshared environmental (including measurement errors) (E) factors. Given that different types of relatives differentially share etiological factors, we made assumptions of correlation between relatives of $\mathrm{A}, \mathrm{D}, \mathrm{C}$, and $\mathrm{E}$ factors, along the lines of prior studies [32, 40, 41]. In particular, the model fitting was performed under the following assumptions: (i) A factors correlate for full siblings at 0.50 and for half siblings at 0.25 , (ii) $\mathrm{D}$ factors correlate for full siblings at 0.25 and do not correlate for half siblings (i.e., at 0), (iii) $\mathrm{C}$ factors entirely correlate for full siblings and maternal half siblings (i.e., at 1) and do not correlate for paternal half siblings, and (iv) E factors do not correlate for any siblings. The analysis was restricted to full siblings and maternal and paternal half siblings. Within clusters, we randomly selected one pair of siblings from each nuclear family, yielding a total sample of 1,493,534 unique dyads. We assumed that OCD, suicide attempts, and deaths by suicide (as dichotomous variables) represent an underlying multivariate normal distribution of liability and that the observed covariates stem from correlation between the liabilities to OCD and suicide outcomes. To establish which factors out of A, D, C, and $\mathrm{E}$ needed to be included in the model to fit, we estimated correlations of OCD with suicide attempts and separately with deaths by suicide within individuals (i.e., phenotypic correlations), between the same trait across siblings (i.e., intraclass correlations), and between trait 1 in one sibling and trait 2 in the other sibling (i.e., cross-sibling cross-trait correlations). We compared the full ADCE model with the reduced submodels $\mathrm{ACE}, \mathrm{ADE}, \mathrm{AE}$, and $\mathrm{CE}$, using a weighted least squares approach with $95 \%$ CIs based on standard errors (Wald CIs). The model with fewer parameters was considered as the best fit, if it was not significantly worse than the full model (by Akaike information criterion and $p$ value for the loss of fit for the reduced models). We controlled for sex and year of birth (continuous) of probands and siblings. Preliminary analyses indicated that adjustment for a continuous instead of categorical variable for year of birth did not change the interpretation of associations.

All tests employed two-tailed significance set at $p<0.05$. Data management was performed using SAS, version 9.4 (SAS Institute, Cary, NC, USA) and analyses were performed using STATA, version 15.1 (StataCorp LLC, College Station, TX, USA), and the package OpenMx [42] in the software R, version 3.4.3 (R Foundation for Statistical Computing, Vienna, Austria).

\section{Results}

\section{Descriptive statistics}

Table 2 presents the characteristics of 3,594,181 cohort members, of which 21,859 were diagnosed with OCD under the study period $(57.59 \%$ female, $n=12,589)$, corresponding to Kaplan-Meier estimate of expected cumulative incidence at age 46 (i.e., at the end of follow-up) of $1.23 \%$ (95\% CI 1.21-1.25\%), under the assumption of no competing risks. Among individuals with OCD, 2984 had attempted suicide and 159 died by suicide during the follow-up. Nearly $75 \%$ of OCD patients had psychiatric comorbidities.

\section{Individual and familial risk of suicide outcomes in association with OCD}

Individuals with OCD had a significantly increased risk of suicide attempts (OR 5.07, 95\% CI 4.88-5.28) and deaths by suicide (OR 4.12, 95\% CI 3.52-4.83), compared to individuals without OCD, in sex- and year of birth-adjusted analysis. The risk of suicide attempts was significantly higher in females (OR 5.62, 95\% CI 5.365.90) than in males (OR 4.23, 95\% CI 3.95-4.53) $(p<$ 0.001 ) as well as the risk of death by suicide (females: OR 5.15, 95\% CI 4.05-6.53, males: OR 3.57, 95\% CI $2.89-4.41 ; p=0.02$ ).

Furthermore, an elevated risk of suicide attempts was observed in all relatives of OCD-probands compared to the relatives of probands without $\mathrm{OCD}$, increasing proportionally to the degree of genetic relatedness (Table 3 and Fig. 1a). The risk of death by suicide also increased alongside narrowing genetic distance revealing the same familial pattern as for suicide attempts. However, wider 95\% CIs pointed towards an underpowered analysis that 
Table 2 Distribution of study characteristics in 3,594,181 birth cohort members

\begin{tabular}{|c|c|c|c|}
\hline Characteristics & $\begin{array}{l}\text { Individuals with OCD } \\
(n=21,859)^{\mathrm{a}}\end{array}$ & $\begin{array}{l}\text { Individuals without OCD } \\
(n=3,572,322)\end{array}$ & $P$-value ${ }^{\mathrm{b}}$ \\
\hline Any suicide attempt, No. (\%) & $2984(13.65)$ & $97,037(2.72)$ & $<0.001$ \\
\hline Male & $947(10.22)$ & $45,220(2.46)$ & $<0.001$ \\
\hline Female & $2037(16.18)$ & $51,817(2.99)$ & $<0.001$ \\
\hline $\begin{array}{l}\text { Age at first suicide attempt, } \\
\text { mean (SD), years }\end{array}$ & $23.05(6.95)$ & $22.60(7.59)$ & 0.001 \\
\hline Male & $24.68(7.22)$ & $23.76(7.82)$ & $<0.001$ \\
\hline Female & $22.30(6.68)$ & $21.59(7.23)$ & $<0.001$ \\
\hline Death by suicide, No. (\%) & $159(0.73)$ & $6746(0.19)$ & $<0.001$ \\
\hline Male & $88(0.95)$ & $4921(0.27)$ & $<0.001$ \\
\hline Female & $71(0.56)$ & $1825(0.11)$ & $<0.001$ \\
\hline $\begin{array}{l}\text { Age at death by suicide, mean } \\
\text { (SD), years }\end{array}$ & $29.33(7.09)$ & $26.93(7.43)$ & $<0.001$ \\
\hline Male & $29.38(6.03)$ & $27.02(7.23)$ & 0.002 \\
\hline Female & $29.26(8.26)$ & $26.69(7.94)$ & 0.01 \\
\hline \multicolumn{4}{|l|}{ Psychiatric comorbidities, No. (\%) } \\
\hline $\begin{array}{l}\text { Any comorbidities (at least } \\
\text { one) }\end{array}$ & $16,331(74.71)$ & $390,734(10.94)$ & $<0.001$ \\
\hline Affective disorders & $10,101(46.21)$ & $166,106(4.65)$ & $<0.001$ \\
\hline Anxiety disorders & $11,331(51.84)$ & $150,096(4.20)$ & $<0.001$ \\
\hline Substance use disorders & $3465(15.85)$ & $130,485(3.65)$ & $<0.001$ \\
\hline Psychotic disorders & $2189(9.88)$ & $26,762(0.75)$ & $<0.001$ \\
\hline Personality disorders & $3353(15.34)$ & $32,153(0.90)$ & $<0.001$ \\
\hline Other psychiatric disorders & $6416(29.35)$ & $128,622(3.60)$ & $<0.001$ \\
\hline
\end{tabular}

$O C D$ obsessive-compulsive disorder, $S D$ standard deviation

a Kaplan-Meier estimate of expected cumulative incidence of OCD at age 46 (i.e., at the end of follow-up) is $1.23 \%$ (95\% CI $1.21-1.25 \%)$, under the assumption of no competing risks

${ }^{\mathrm{b}} P$ values are estimated by chi-square test and Fisher's exact test for categorical variables and independentsample two-tailed $t$ tests for continuous variables was anticipated due to the small number of deaths by suicide (Table 3 and Fig. 1b).

\section{Sensitivity analyses}

When we excluded relatives with OCD and probands with any suicidal outcomes from the analysis of OCD and suicide attempts, all ORs were slightly attenuated, yet remained significant, except for paternal half siblings (Fig. 1a and Supplementary Table 2). For deaths by suicide, the ORs diminished in all relative clusters, yet the increased risks among parents and full siblings remained significant (Fig. 1b and Supplementary Table 2).

When probands and relatives with psychiatric comorbidities were excluded, the risks for OCD and suicide attempts, as well as for OCD and death by suicide, were attenuated, although the patterns of risk across relatives remained mainly the same (Supplementary Table 3).

Finally, our effort to overcome the follow-up bias by excluding all migrations and deaths did not alter any previous results (Supplementary Table 4).

\section{Quantitative genetic modeling}

Table 4 reports sex- and year of birth-adjusted phenotypic, intraclass, and cross-trait cross-sibling correlations of OCD with suicide outcomes. The phenotypic correlation between OCD and suicide attempts within individuals was 0.30 (95\% CI 0.29-0.31). Intraclass and cross-trait cross-sibling correlations were higher in full siblings than in maternal half siblings. Cross-trait cross-sibling correlations were similar in maternal and paternal half siblings. The ACE submodel provided the best fit (Supplementary Table 5). As a result, $60.7 \%$ (95\% CI 32.1-89.4) of phenotypic correlation between OCD and suicide attempts appeared to be explained by additive genetics and 40.4\% (95\% CI $24.2-$ 56.6) were attributable to nonshared environment. The contribution of shared environment was negligible $(-1.2 \%$; $95 \%$ CI -14.8 to 12.5$)$.

The phenotypic correlation between OCD and death by suicide was 0.19 (95\% CI 0.16-0.21) (Table 4). All correlations in maternal half siblings were less than half of that in full siblings, while cross-trait cross-sibling correlations were 
Table 3 Familial coaggregation of OCD with suicide attempts and death by suicide across different types of relatives

\begin{tabular}{|c|c|c|c|c|c|}
\hline & \multicolumn{2}{|c|}{ Relatives of OCD-probands } & \multicolumn{2}{|c|}{ Relatives of non-OCD-probands } & \multirow[t]{2}{*}{ OR $(95 \% \mathrm{CI})^{\mathrm{a}}$} \\
\hline & Total, no. & Suicide outcome, no. (\%) & Total, no. & Suicide outcome, no. (\%) & \\
\hline \multicolumn{6}{|l|}{ Suicide attempts } \\
\hline Parents - offspring & 21,593 & $2112(9.78)$ & $3,538,427$ & $226,647(6.41)$ & $1.56(1.49-1.63)^{\mathrm{b}}$ \\
\hline Full siblings & 24,910 & $1190(4.78)$ & $4,118,614$ & $115,661(2.81)$ & $1.63(1.53-1.73)$ \\
\hline Maternal half siblings & 5806 & $359(6.18)$ & 708,924 & $36,303(5.12)$ & $1.21(1.08-1.36)$ \\
\hline Paternal half siblings & 6282 & $338(5.38)$ & 826,296 & $38,425(4.65)$ & $1.19(1.06-1.33)$ \\
\hline Full cousins & 85,070 & $3024(3.55)$ & $13,749,812$ & $434,302(3.16)$ & $1.11(1.07-1.16)$ \\
\hline \multicolumn{6}{|l|}{ Death by suicide } \\
\hline Parents - offspring & 21,593 & $365(1.69)$ & $3,538,427$ & $37,540(1.06)$ & $1.55(1.40-1.72)^{b}$ \\
\hline Full siblings & 24,910 & $79(0.32)$ & $4,118,614$ & $7066(0.17)$ & $1.80(1.43-2.26)$ \\
\hline Maternal half siblings & 5806 & $27(0.47)$ & 708,924 & $2318(0.33)$ & $1.29(0.86-1.94)$ \\
\hline Paternal half siblings & 6282 & $24(0.38)$ & 826,296 & $2487(0.30)$ & $1.27(0.85-1.89)$ \\
\hline Full cousins & 85,070 & $172(0.20)$ & $13,749,812$ & $24,912(0.18)$ & $1.09(0.94-1.28)$ \\
\hline
\end{tabular}

Note: Parents are included in the analysis of "parents-offspring" cluster if none of them have died/emigrated from Sweden (and never returned) prior to 1973. Parents are considered as cases for suicide behavior if at least one parent has a corresponding outcome, i.e., attempted suicide or died from suicide. The significant results are highlighted in bold type

$O C D$ obsessive-compulsive disorder, OR odds ratio, $95 \%$ CI $95 \%$ confidence interval

${ }^{a}$ Adjusted for sex and birth year (categorized by 10 -year increments) of both probands and relatives

${ }^{\mathrm{b}}$ Adjusted for sex and birth year (categorized by 10-year increments) of the probands

higher in paternal than in maternal half siblings. AE submodel provided the best fit (Supplementary Table 6). The phenotypic correlation between OCD and death by suicide was explained by additive genetics $(65.8 \%$; $95 \%$ CI $25.9-$ 105.6) and nonshared environment $(34.2 \%$; $95 \% \mathrm{CI}-5.6$ to 74.1). However, the analyses were underpowered, with the full ADCE model being numerically unstable.

\section{Discussion}

This population-based birth cohort study is the first to explore familial coaggregation of OCD and suicide outcomes and to quantify the contribution of genetic and environmental factors to familial liability. Four main findings emerged. First, confirming previous studies conducted in clinical and community settings [1-5, 43-46], individuals with OCD were at significantly increased risk of suicide attempts and death by suicide compared to individuals without $\mathrm{OCD}$, and the risks were more pronounced for female than male OCD sufferers, similar to the results of another Swedish study on OCD and suicide [2]. This was anticipated in relation to suicide attempts, as nonfatal suicidal behavior is known to be more common in females [28, 47]. A corresponding higher risk for death by suicide can stem from relatively similar proportions of females and males who died by suicide in the OCD group, while in the general population, females were considerably less likely to die by suicide, compared to males [28, 47].
Overall, our estimates for death by suicide likely represent an underestimation of the actual risk due to the young age of the cohort. Indeed, in a previous Swedish register study [2], the mean age at death by suicide was 42.5 years (vs. 29.3 years in the current study), resulting in an OR of 9.83 (vs. 4.12 in the current study). Despite the fact that death by suicide is relatively uncommon among OCD sufferers $(0.73 \%$ in OCD patients and $0.19 \%$ in individuals without OCD), the reported proportions of suicide attempts $(13.65 \%$ in OCD patients and $2.72 \%$ in individuals without OCD), together with previous findings, challenge the traditional view of OCD as a low risk disorder for suicidal behavior.

Second, the patterns of risk of suicide attempts and deaths by suicide that appeared among the relatives of OCD-probands, with the strength of associations increasing proportionally to the degree of genetic relatedness, suggest that familial risk factors underlie, at least partly, an association between OCD and suicide outcomes. A contribution of genetic factors was further supported by the risk of suicide attempts being higher in full siblings compared to maternal half siblings as these types of relatives share a substantial amount of environment as they grow up but differ on the proportion of shared cosegregating alleles (50\% vs. $25 \%$, respectively). A minor potential role of familial environment was apparent from the rather negligible difference in risks observed in maternal and paternal half siblings given that these relative categories both share $25 \%$ of additive genetics, but maternal half siblings tend to 


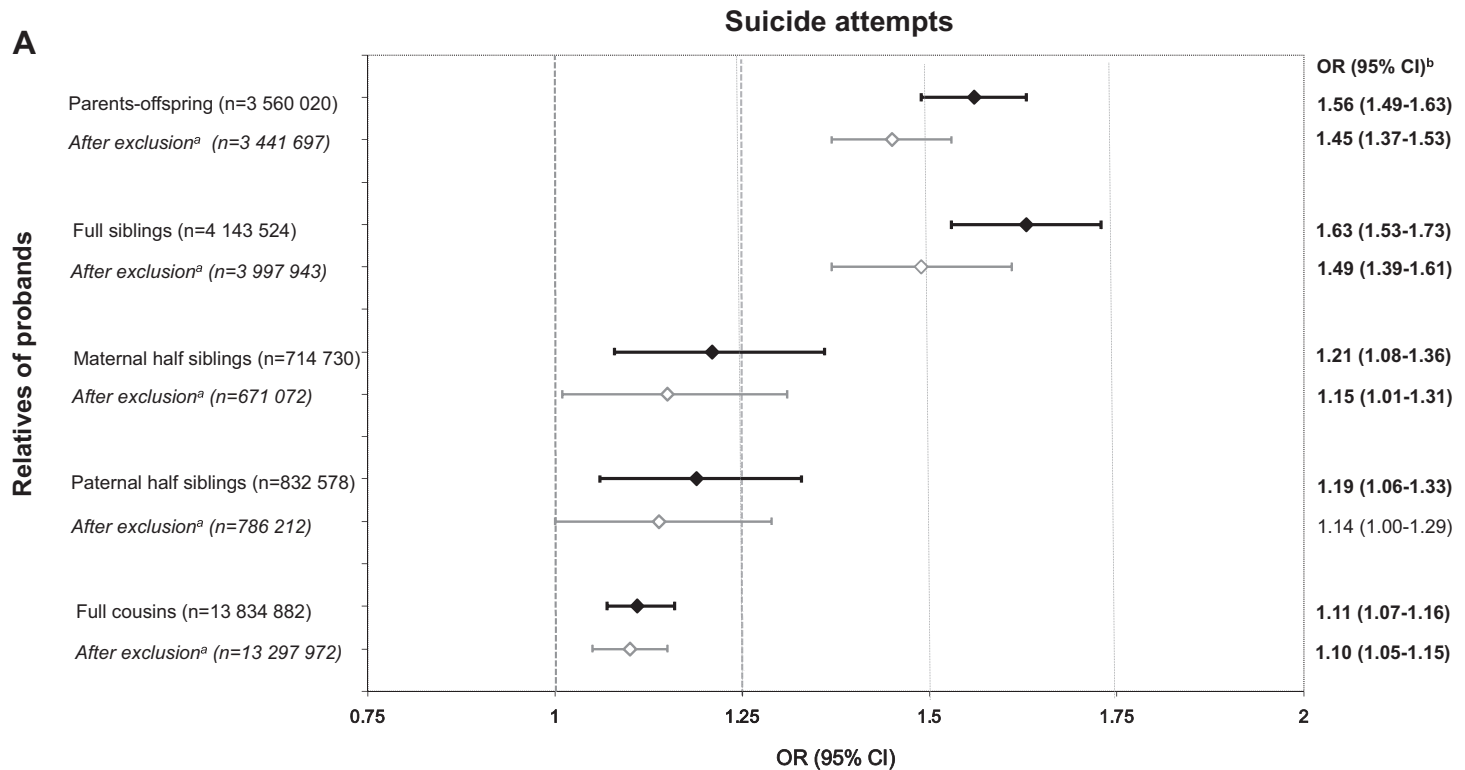

B

Death by suicide

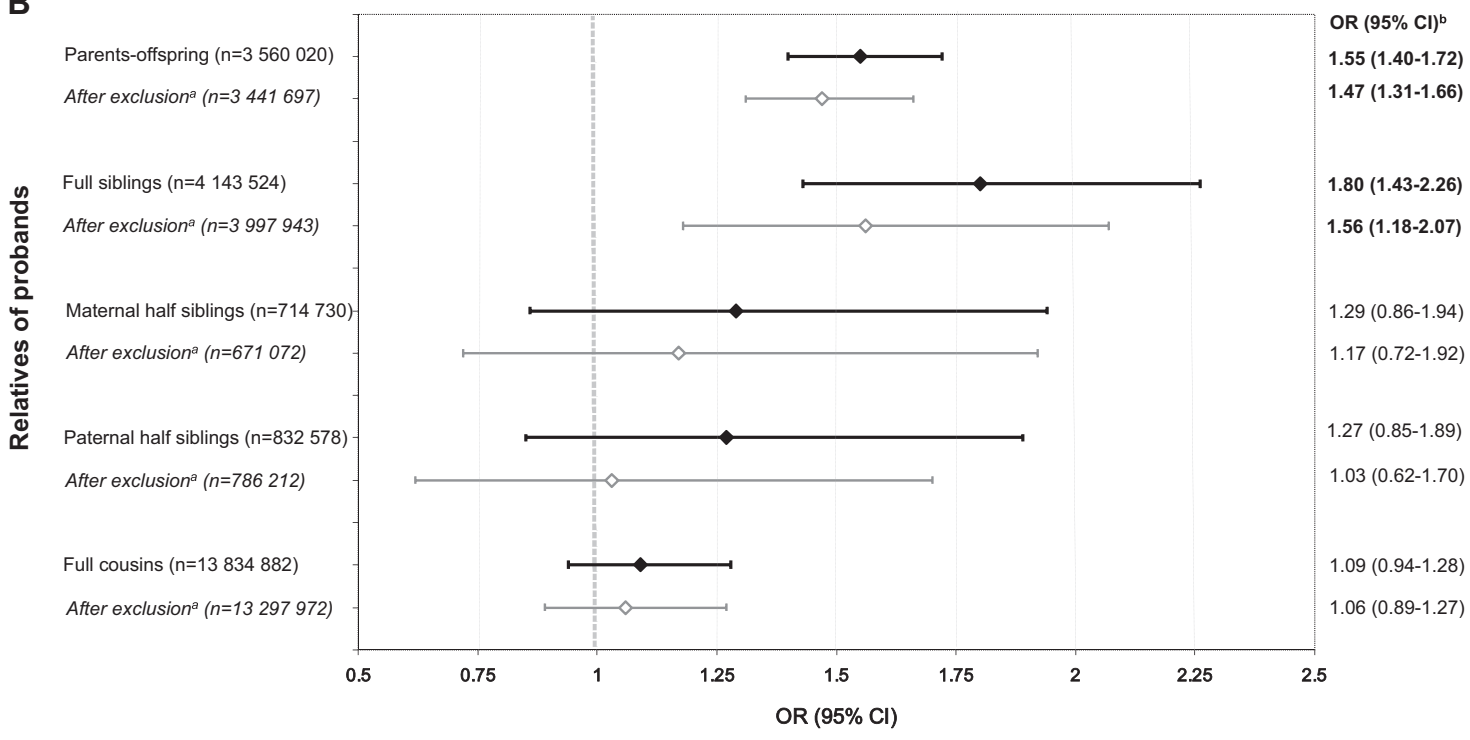

Fig. 1 Familial coaggregation between $\mathrm{OCD}$ and suicide attempts (panel a) and death by suicide (panel b) across different types of relatives, before and after excluding probands with any suicidal behavior and relatives with OCD. Note: Numbers in parentheses are the number of observations included in the analysis (i.e., all possible combinations of pairs in which members contribute to the analysis with information on OCD and suicide attempts (panel a) or death by suicide (panel b). Parents are included in the analysis of "parents -offspring" cluster if none of them have died/emigrated from Sweden (and never returned) prior to 1973. Parents are considered as cases if at

share more environmental factors. An underpowered analysis of coaggregation between OCD and death by suicide precluded us from drawing definite conclusions, although the higher risk of death by suicide in full siblings, compared to maternal half siblings, suggests a possible contribution of genetic factors. A sensitivity analysis further supported the familial coaggregation of OCD with suicide outcomes, least one parent has attempted suicide (panel a) or died from suicide (panel b). The significant results are highlighted in bold type. ${ }^{a}$ After excluding probands with any suicide attempt or a record of death by suicide and relatives with OCD (the sensitivity analysis on the direct effect of OCD on suicide outcomes within an individual). ${ }^{\mathrm{b}}$ Adjusted for sex and birth year (categorized by 10-year increments) of both probands and relatives (only for proband's sex and year of birth in "parents-offspring" cluster). $O C D$ obsessive-compulsive disorder, OR odds ratio, $95 \%$ CI $95 \%$ confidence interval

rather than the direct effect of OCD on suicidal behavior within an individual.

Third, quantitative genetic modeling confirmed observations from the family data to indicate that genetic factors largely explain the phenotypic cross-disorder correlations, though the contribution of genetic factors is slightly more pronounced for coaggregation of OCD and death by suicide 


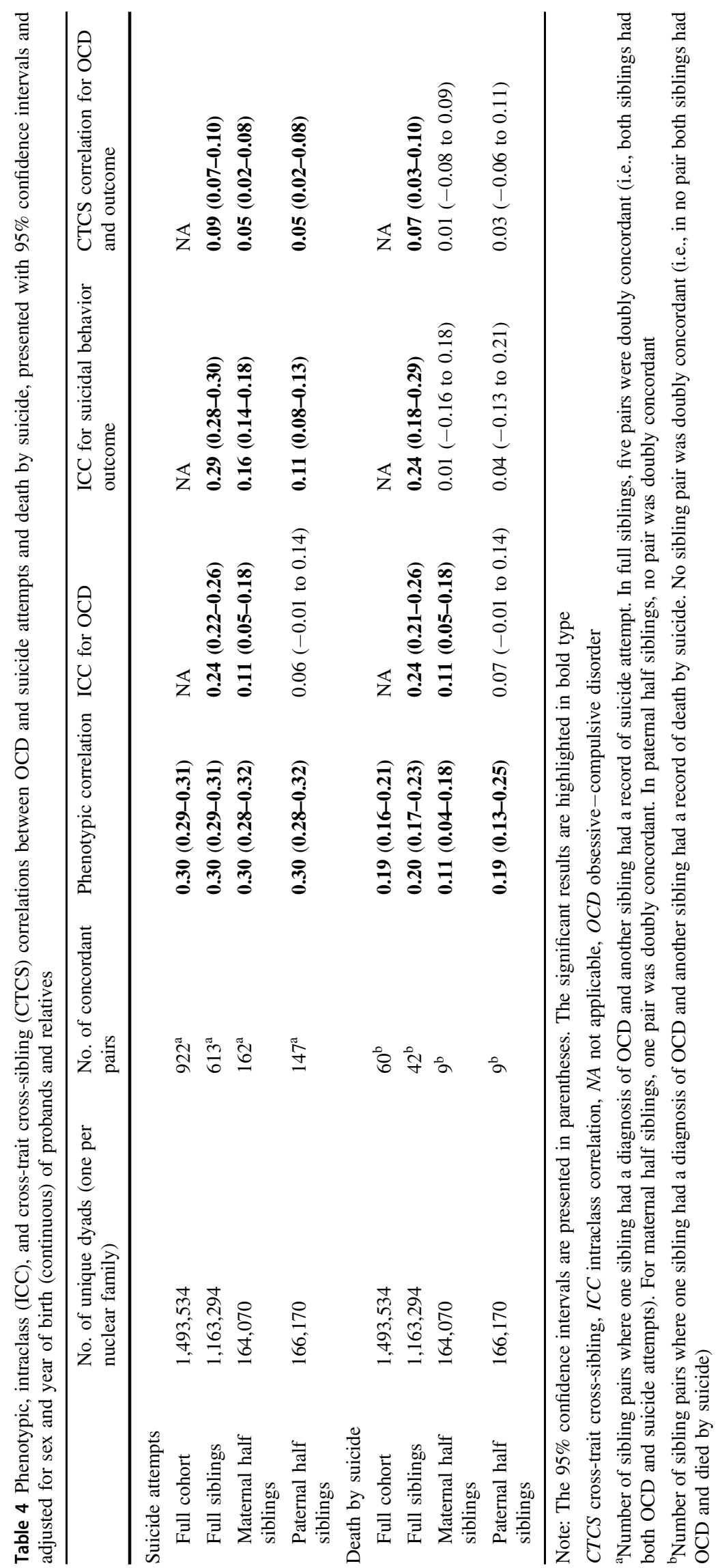


$(66 \%)$ than that of OCD and suicide attempts (60\%). With samples of genotyped individuals with OCD and suicidal behavior increasing worldwide, it is expected that the current results will be replicated and confirmed at the molecular genetic level. If biological pleiotropy is demonstrated, one implication for future research is that identification of genes implicated in OCD may theoretically also shed light on genetic variants that increase risk of suicide, and vice versa.

Fourth, in our study, a smaller but substantial part of familial coaggregation was attributed to nonshared environment (34\% for OCD and death by suicide and $40 \%$ for OCD and suicide attempts). This suggests that suicidal behavior can also be partially conceptualized as a functional consequence of OCD, a chronic disorder that substantially impairs the person's quality of life [48, 49] and ability to fully participate in society $[50,51]$. This is a particularly important finding since a deeper knowledge of these unique risk factors has the potential to improve identification of OCD patients at high risk of suicidal behaviors and provide a window of opportunity for the design and implementation of targeted preventive interventions in individuals at-risk. In addition, unique environmental factors, if modifiable, may serve as intervention targets themselves and thus be "proxy" targets for suicide prevention in OCD patients (e.g., treatment of comorbid psychiatric comorbidities, increase of social support). Taken together, our findings warrant further research into potential evocative gene-environment correlations where genetically influenced behavior (i.e., OCD) may in turn influence the environment [48-53] in a way that the risk of suicide is increased [28, 54-58] (e.g., social isolation, academic underachievement, unemployment, low socioeconomic level, being unmarried, poor quality of life).

\section{Strengths and limitations}

Along with a large study size, the strengths of the study include the use of nationwide Swedish registers with prospective and uniformed data collection which minimizes the risk of selection, recall, and report biases. The completeness of the MGR [17] ensured ascertainment of a large sample of relatives with different shares of common genetic and environmental factors that allowed an assessment of familial coaggregation in distinct relative clusters. Furthermore, our definitions of clinical cases have previously been validated for Swedish data on OCD [21], many psychiatric comorbidities [59-62], and death by suicide [25, 63], which decreases diagnostic misclassification. The findings were largely unchanged in various sensitivity analyses where psychiatric comorbidities were taken into account.

Several limitations should also be considered. First, the study cohort does not represent the totality of individuals in Sweden with OCD or suicide attempts due to a number of reasons: (i) not all OCD sufferers seek help [64-66] and low rates of healthcare utilization are known for suicide attempts due to the sensitive nature of these behaviors and given that not all self-harm cases need inpatient or specialized outpatient treatment $[67,68]$; (ii) the coverage of the NPR is incomplete since prior to 2001 only hospital admissions were registered; and (iii) the NPR does not include diagnostic information from primary care services or nonmedical specialists [18]. Second, compared to the higher validity of ICD-10 codes for OCD, the validity of ICD-8 and ICD-9 codes is slightly lower [19]. While this should not be crucial for our cohort members with only $1.53 \%$ of OCD cases never (re-)appearing in ICD-10, it may affect the collection of parental OCD used in the sensitivity analysis. Third, data on biological paternity in the MGR are self-reported by the mother and can be inaccurate. However, in an international review [69], paternal discrepancy was reported to be low (median 3.7\%). Fourth, despite a large study size, our analyses were underpowered for capturing associations between OCD and death by suicide. Small number of cases also affected the stability of the models in quantitative genetic analyses. Fifth, out of the factors that are potentially shared between OCD and suicidal behavior and can explain their familial coaggregation, we only controlled for the impact of psychiatric comorbidities. Due to data unavailability, we could not explore the impact of, for example, childhood trauma (i.e., abuse and neglect), which is thought to predispose individuals for the development of both OCD and suicidal behavior [70, 71]. Finally, a tendency to joint physical custody, that currently applies to $30 \%$ of Swedish children after parental separation [72], might have diminished the difference in shared environment between maternal and paternal half siblings.

\section{Conclusions}

The relation between OCD and suicidal behavior appears to be complex. Although genetic factors largely underlie familial coaggregation between OCD and both outcomes, the contribution of the unique nonshared environment is also considerable and suggests an opportunity for prevention and intervention in high-risk individuals.

Acknowledgements This work was supported by a Junior Researcher grant from the Swedish Research Council for Health, Working Life and Welfare (FORTE grant number 2015-00569) awarded to LFC. The funders had no role in the design and conduct of the study; collection, management, analysis, and interpretation of the data; preparation, review, or approval of the manuscript; and decision to submit the manuscript for publication.

\section{Compliance with ethical standards}

Conflict of interest LFC and DM-C receive royalties for contributing articles to UpToDate, Wolters Kluwer Health. HL has served as a speaker for Evolan and Shire and has received research grants from 
Shire, all outside of the submitted work. The remaining authors declare that they have no conflict of interest.

Publisher's note: Springer Nature remains neutral with regard to jurisdictional claims in published maps and institutional affiliations.

Open Access This article is licensed under a Creative Commons Attribution 4.0 International License, which permits use, sharing, adaptation, distribution and reproduction in any medium or format, as long as you give appropriate credit to the original author(s) and the source, provide a link to the Creative Commons license, and indicate if changes were made. The images or other third party material in this article are included in the article's Creative Commons license, unless indicated otherwise in a credit line to the material. If material is not included in the article's Creative Commons license and your intended use is not permitted by statutory regulation or exceeds the permitted use, you will need to obtain permission directly from the copyright holder. To view a copy of this license, visit http://creativecommons. org/licenses/by/4.0/.

\section{References}

1. Alonso P, Segalas C, Real E, Pertusa A, Labad J, Jimenez-Murcia $\mathrm{S}$, et al. Suicide in patients treated for obsessive-compulsive disorder: a prospective follow-up study. J Affect Disord. 2010;124:300-8.

2. Fernández de la Cruz L, Rydell M, Runeson B, D’Onofrio BM, Brander G, Rück C, et al. Suicide in obsessive-compulsive disorder: a population-based study of 36788 Swedish patients. Mol Psychiatry. 2017;22:1626-32.

3. Meier SM, Mattheisen M, Mors O, Schendel DE, Mortensen PB, Plessen KJ. Mortality among persons with obsessive-compulsive disorder in Denmark. JAMA Psychiatry. 2016;73:268-74.

4. Albert U, De Ronchi D, Maina G, Pompili M. Suicide risk in obsessive-compulsive disorder and exploration of risk factors: a systematic review. Curr Neuropharmacol. 2018; e-pub ahead of print 2018; https://doi.org/10.2174/1570159X16666180620155941.

5. Heun R. Increased risk of attempted and completed suicide in obsessive compulsive disorder: a systematic review of follow-up studies. GlobalPsychiatry. 2018;1:61-70. https://doi.org/10.2478/ gp-2018-0009.

6. Mataix-Cols D, Boman M, Monzani B, Rück C, Serlachius E, Langstrom N, et al. Population-based, multigenerational family clustering study of obsessive-compulsive disorder. JAMA Psychiatry. 2013;70:709-17.

7. Pauls DL, Abramovitch A, Rauch SL, Geller DA. Obsessivecompulsive disorder: an integrative genetic and neurobiological perspective. Nat Rev Neurosci. 2014;15:410-24.

8. Taylor S. Etiology of obsessions and compulsions: a metaanalysis and narrative review of twin studies. Clin Psychol Rev. 2011;31:1361-72.

9. Fu Q, Heath AC, Bucholz KK, Nelson EC, Glowinski AL, Goldberg $\mathrm{J}$, et al. A twin study of genetic and environmental influences on suicidality in men. Psychol Med. 2002;32:11-24.

10. Glowinski AL, Bucholz KK, Nelson EC, Fu Q, Madden PA, Reich W, et al. Suicide attempts in an adolescent female twin sample. J Am Acad Child Adolesc Psychiatry. 2001;40:1300-7.

11. Statham DJ, Heath AC, Madden PA, Bucholz KK, Bierut L, Dinwiddie SH, et al. Suicidal behaviour: an epidemiological and genetic study. Psychol Med. 1998;28:839-55.

12. Tidemalm D, Runeson B, Waern M, Frisell T, Carlstrom E, Lichtenstein $\mathrm{P}$, et al. Familial clustering of suicide risk: a total population study of 11.4 million individuals. Psychol Med. 2011;41:2527-34.
13. Runeson B, Asberg M. Family history of suicide among suicide victims. Am J Psychiatry. 2003;160:1525-6.

14. Yao S, Kuja-Halkola R, Thornton LM, Runfola CD, D'Onofrio BM, Almqvist C, et al. Familial liability for eating disorders and suicide attempts: evidence from a population registry in Sweden. JAMA Psychiatry. 2016;73:284-91.

15. Ljung T, Chen Q, Lichtenstein P, Larsson H. Common etiological factors of attention-deficit/hyperactivity disorder and suicidal behavior: a population-based study in Sweden. JAMA Psychiatry. 2014;71:958-64.

16. Ludvigsson JF, Otterblad-Olausson P, Pettersson BU, Ekbom A. The Swedish personal identity number: possibilities and pitfalls in healthcare and medical research. Eur J Epidemiol. 2009;24:65967.

17. Ekbom A. The Swedish Multi-generation register. Methods Mol Biol. 2011;675:215-20.

18. Ludvigsson JF, Andersson E, Ekbom A, Feychting M, Kim JL, Reuterwall C, et al. External review and validation of the Swedish national inpatient register. BMC Public Health. 2011;11:450.

19. Brooke HL, Talback M, Hornblad J, Johansson LA, Ludvigsson $\mathrm{JF}$, Druid $\mathrm{H}$, et al. The Swedish cause of death register. Eur J Epidemiol. 2017;32:765-73.

20. Ludvigsson JF, Almqvist C, Bonamy AK, Ljung R, Michaelsson K, Neovius M, et al. Registers of the Swedish total population and their use in medical research. Eur J Epidemiol. 2016;31:125-36.

21. Rück C, Larsson KJ, Lind K, Pérez-Vigil A, Isomura K, Sariaslan $\mathrm{A}$, et al. Validity and reliability of chronic tic disorder and obsessive-compulsive disorder diagnoses in the Swedish National Patient Register. BMJ Open. 2015;5:e007520.

22. Runeson B, Tidemalm D, Dahlin M, Lichtenstein P, Langstrom N. Method of attempted suicide as predictor of subsequent successful suicide: national long term cohort study. BMJ. 2010;341:c3222.

23. Neeleman J, Wessely S. Changes in classification of suicide in England and Wales: time trends and associations with coroners' professional backgrounds. Psychol Med. 1997;27:467-72.

24. Ohberg A, Lonnqvist J. Suicides hidden among undetermined deaths. Acta Psychiatr Scand. 1998;98:214-8.

25. Rockett IR, Thomas BM. Reliability and sensitivity of suicide certification in higher-income countries. Suicide Life Threat Behav. 1999;29:141-9.

26. Niederkrotenthaler T, Floderus B, Alexanderson K, Rasmussen F, Mittendorfer-Rutz E. Exposure to parental mortality and markers of morbidity, and the risks of attempted and completed suicide in offspring: an analysis of sensitive life periods. J Epidemiol Community Health. 2012;66:233-9.

27. Nock MK, Hwang I, Sampson N. Cross-national analysis of the associations among mental disorders and suicidal behavior: findings from the WHO World Mental Health Surveys. PLoS Med. 2009;6:e1000123.

28. Turecki G, Brent DA. Suicide and suicidal behaviour. Lancet. 2016;387:1227-39.

29. StataCorp. Stata 15 Base Reference Manual. Logistic regression, reporting odds ratios. College Station, TX: Stata Press; 2017. https://www.stata.com/manuals/rlogistic.pdf. Accessed 5 March 2019.

30. Williams RL. A note on robust variance estimation for clustercorrelated data. Biometrics. 2000;56:645-6.

31. StataCorp. Stata 15 Base Reference Manual. Variance estimators. College Station, TX: Stata Press; 2017. https://www.stata.com/ma nuals/rvce_option.pdf. Accessed 5 March 2019.

32. Brikell I, Ghirardi L, D’Onofrio BM, Dunn DW, Almqvist C, Dalsgaard S, et al. Familial liability to epilepsy and attentiondeficit/hyperactivity disorder: a nationwide cohort study. Biol Psychiatry. 2018;83:173-80.

33. Statistics Sweden. Different families live in different ways-a survey on residence and support of children after a separation. 
Örebro: Statistics Sweden; 2014. https://www.scb.se/Statistik/_ Publikationer/BE0701_2013A01_BR_BE51BR1401.pdf. Accessed 4 March 2019.

34. Brander G, Rydell M, Kuja-Halkola R, Fernández de la Cruz L, Lichtenstein P, Serlachius E, et al. Association of perinatal risk factors with obsessive-compulsive disorder: a population-based birth cohort, sibling control study. JAMA Psychiatry. 2016;73:1135-44.

35. Niederkrotenthaler T, Rasmussen F, Mittendorfer-Rutz E. Perinatal conditions and parental age at birth as risk markers for subsequent suicide attempt and suicide: a population based casecontrol study. Eur J Epidemiol. 2012;27:729-38.

36. Chen Q, Kuja-Halkola R, Sjolander A, Serlachius E, Cortese S, Faraone SV, et al. Shared familial risk factors between attentiondeficit/hyperactivity disorder and overweight/obesity-a population-based familial coaggregation study in Sweden. J Child Psychol Psychiatry. 2017;58:711-8.

37. Hudson JI, Javaras KN, Laird NM, VanderWeele TJ, Pope HG Jr, Hernan MA. A structural approach to the familial coaggregation of disorders. Epidemiology. 2008;19:431-9.

38. Rijsdijk FV, Sham PC. Analytic approaches to twin data using structural equation models. Brief Bioinform. 2002;3:119-33.

39. Verweij KJ, Mosing MA, Zietsch BP, Medland SE. Estimating heritability from twin studies. Methods Mol Biol. 2012;850:151-70.

40. Mataix-Cols D, Isomura K, Pérez-Vigil A, Chang Z, Rück C, Larsson KJ, et al. Familial risks of Tourette syndrome and chronic tic disorders. a population-based cohort study. JAMA Psychiatry. 2015;72:787-93

41. Sandin S, Lichtenstein P, Kuja-Halkola R, Larsson H, Hultman CM, Reichenberg A. The familial risk of autism. JAMA. 2014;311:1770-7.

42. Neale MC, Hunter MD, Pritikin JN, Zahery M, Brick TR, Kirkpatrick RM, et al. Openmx 2.0: extended structural equation and statistical modeling. Psychometrika. 2016;81:535-49.

43. Angelakis I, Gooding P, Tarrier N, Panagioti M. Suicidality in obsessive compulsive disorder (OCD): a systematic review and meta-analysis. Clin Psychol Rev. 2015;39:1-15.

44. Velloso P, Piccinato C, Ferrao Y, Aliende Perin E, Cesar R, Fontenelle L, et al. The suicidality continuum in a large sample of obsessive-compulsive disorder (OCD) patients. Eur Psychiatry. 2016;38:1-7.

45. Dell'Osso B, Benatti B, Arici C, Palazzo C, Altamura AC, Hollander E, et al. Prevalence of suicide attempt and clinical characteristics of suicide attempters with obsessive-compulsive disorder: a report from the International College of ObsessiveCompulsive Spectrum Disorders (ICOCS). CNS Spectr. 2018;23:59-66.

46. Torres AR, Ramos-Cerqueira AT, Ferrao YA, Fontenelle LF, do Rosario MC, Miguel EC. Suicidality in obsessive-compulsive disorder: prevalence and relation to symptom dimensions and comorbid conditions. J Clin Psychiatry. 2011;72:17-26.

47. World Health Organization (WHO). Preventing suicide: a global imperative. Geneva: WHO Press; 2014. http://www.who.int. Accessed 4 March 2019.

48. Macy AS, Theo JN, Kaufmann SC, Ghazzaoui RB, Pawlowski PA, Fakhry HI, et al. Quality of life in obsessive compulsive disorder. CNS Spectr. 2013;18:21-33.

49. Coluccia A, Ferretti F, Fagiolini A, Pozza A. Quality of life in children and adolescents with obsessive-compulsive disorder: a systematic review and meta-analysis. Neuropsychiatr Dis Treat. 2017;13:597-608.

50. Pérez-Vigil A, Mittendorfer-Rutz E, Helgesson M, Fernández de la Cruz L, Mataix-Cols D. Labour market marginalisation in obsessive-compulsive disorder: a nationwide register-based sibling control study. Psychol Med. 2018; e-pub ahead of print 28 June 2018; https://doi.org/10.1017/S0033291718001691.
51. Pérez-Vigil A, Fernández de la Cruz L, Brander G, Isomura K, Jangmo A, Feldman I, et al. Association of obsessive-compulsive disorder with objective indicators of educational attainment: a nationwide register-based sibling control study. JAMA Psychiatry. 2018;75:47-55.

52. Grisham JR, Fullana MA, Mataix-Cols D, Moffitt TE, Caspi A, Poulton R. Risk factors prospectively associated with adult obsessive-compulsive symptom dimensions and obsessivecompulsive disorder. Psychol Med. 2011;41:2495-506.

53. Fontenelle LF, Hasler G. The analytical epidemiology of obsessive-compulsive disorder: risk factors and correlates. Prog Neuropsychopharmacol Biol Psychiatry. 2008;32:1-15.

54. Batty GD, Kivimäki M, Bell S, Gale CR, Shipley M, Whitley E, et al. Psychosocial characteristics as potential predictors of suicide in adults: an overview of the evidence with new results from prospective cohort studies. Transl Psychiatry. 2018;8:22 https:// doi.org/10.1038/s41398-017-0072-8

55. Tsai AC, Lucas M, Kawachi I. Association between social integration and suicide among women in the United States. JAMA Psychiatry. 2015;22:987-93.

56. Sorberg Wallin A, Zeebari Z, Lager A, Gunnell D, Allebeck P, Falkstedt D. Suicide attempt predicted by academic performance and childhood IQ: a cohort study of 26000 children. Acta Psychiatr Scand. 2018;137:277-86.

57. Gajewski P, Zhukovska K. Short-run and long-run effects of unemployment on suicides: does welfare regime matter? Eur J Public Health. 2017;27:1038-42.

58. Alves Vde M, Francisco LC, Belo FM, de-Melo-Neto VL, Barros VG, Nardi AE. Evaluation of the quality of life and risk of suicide. Clinics (Sao Paulo). 2016;71:135-9.

59. Dalman C, Broms J, Cullberg J, Allebeck P. Young cases of schizophrenia identified in a national inpatient register-are the diagnoses valid? Soc Psychiatry Psychiatr Epidemiol. 2002;37:527-31.

60. Ekholm B, Ekholm A, Adolfsson R, Vares M, Osby U, Sedvall GC, et al. Evaluation of diagnostic procedures in Swedish patients with schizophrenia and related psychoses. Nord J Psychiatry. 2005;59:457-64.

61. Idring S, Rai D, Dal H, Dalman C, Sturm H, Zander E, et al. Autism spectrum disorders in the Stockholm Youth Cohort: design, prevalence and validity. PLoS ONE. 2012;7:e41280.

62. Sellgren C, Landen M, Lichtenstein P, Hultman CM, Langstrom $\mathrm{N}$. Validity of bipolar disorder hospital discharge diagnoses: file review and multiple register linkage in Sweden. Acta Psychiatr Scand. 2011;124:447-53.

63. de Faire U, Friberg L, Lorich U, Lundman T. A validation of cause-of-death certification in 1,156 deaths. Acta Med Scand. 1976;200:223-8.

64. Fullana MA, Mataix-Cols D, Caspi A, Harrington H, Grisham JR, Moffitt TE, et al. Obsessions and compulsions in the community: prevalence, interference, help-seeking, developmental stability, and co-occurring psychiatric conditions. Am J Psychiatry. 2009;166:329-36.

65. Garcia-Soriano G, Rufer M, Delsignore A, Weidt S. Factors associated with non-treatment or delayed treatment seeking in OCD sufferers: a review of the literature. Psychiatry Res. 2014;220:1-10.

66. Torres AR, Prince MJ, Bebbington PE, Bhugra DK, Brugha TS, Farrell M, et al. Treatment seeking by individuals with obsessivecompulsive disorder from the british psychiatric morbidity survey of 2000. Psychiatr Serv. 2007;58:977-82.

67. Piscopo K, Lipari RN, Cooney J, Glasheen C. Suicidal thoughts and behavior among adults: results from the 2015 national survey on drug use and health. NSDUH Data Review 2016. https://www. samhsa.gov/data/sites/default/files/NSDUH-DR-FFR3-2015/ NSDUH-DR-FFR3-2015.pdf. Accessed 4 March 2019. 
68. Ramberg IL, Wasserman D. Prevalence of reported suicidal behaviour in the general population and mental health-care staff. Psychol Med. 2000;30:1189-96.

69. Bellis MA, Hughes K, Hughes S, Ashton JR. Measuring paternal discrepancy and its public health consequences. J Epidemiol Community Health. 2005;59:749-54.

70. Khosravani V, Kamali Z, Jamaati Ardakani R, Samimi Ardestani $\mathrm{M}$. The relation of childhood trauma to suicide ideation in patients suffering from obsessive-compulsive disorder with lifetime suicide attempts. Psychiatry Res. 2017;255:139-45.

71. Ay R, Erbay LG. Relationship between childhood trauma and suicide probability in obsessive-compulsive disorder. Psychiatry Res. 2018;261:132-6.

72. Bergstrom M, Modin B, Fransson E, et al. Living in two homesa Swedish national survey of wellbeing in 12 and 15 year olds with joint physical custody. BMC Public Health. 2013;13:868. 